\title{
Numerical Simulation and Optimization of an Industrial Fluid Catalytic Cracking Regenerator
}

\section{Guangwu Tang}

Center for Innovation through Visualization and Simulation,

Purdue University Northwest

2200169 th Street

Hammond, IN, 46323

219-671-3423 Email:tangg@pnw.edu

Bin Wu

Center for Innovation through Visualization and Simulation,

Purdue University Northwest

2200169 th Street

Hammond, IN, 46323

219-989-3157 Email:wu7@pnw.edu

Dwight Agnello-Dean

BP Company North America

East Chicago, IN 46323

219-787-3446 Email: Dwight.Agnello-Dean@bp.com

\section{Qingjun Meng}

BP Refining and Logistics Technology

Naperville, IL, 60563

219-787-3446 Email: qingjun.meng@bp.com

Chenn Q. Zhou (Corresponding Author)

Center for Innovation through Visualization and Simulation,

Purdue University Northwest

2200 169th Street

Hammond, IN, 46323

219-256-2665 Email: czhou@pnw.edu

\section{Armin K. Silaen}

Center for Innovation through Visualization and Simulation,

Purdue University Northwest

2200 169th Street

Hammond, IN, 46323

219-989-3157 Email: asilaen@pnw.edu

\section{Dong Fu}

Center for Innovation through Visualization and Simulation,

Purdue University Northwest

2200 169th Street

Hammond, IN, 46323

219-989-3157 Email: fudong1985@gmail.com

\section{Joseph Wilson}

BP Refining and Logistics Technology

Naperville, IL, 60563

219-787-3446 Email: Joseph.Wilson2@bp.com

\section{Samir Khanna}

BP Refining and Logistics Technology

Naperville, IL, 60563

219-787-3446 Email: samir.khanna@bp.com

(C) 2016. This manuscript version is made available under the Elsevier user license 
Abstract: Fluid catalytic cracking (FCC) is one of the most important conversion processes in petroleum refineries. FCC regenerator is a key part of an FCC unit to recover the solid catalyst reactivity by burning off the deposited coke on the catalyst. In this paper, a three-dimensional multi-phase, multi-species reacting flow computational fluid dynamics (CFD) model was established to simulate the flow and the reactions inside an FCC regenerator. The Euler-Euler approach, where the two phases (gas and solid) are considered to be continuous and fully interpenetrating, is employed. A modified drag force model was applied on the CFD model with appropriate influential cluster diameters of particle grouping phenomenon. The developed CFD model was validated by using plant data. With the validated CFD model, the flow characteristics and the inner-phase and inter-phase reactions were studied. The results showed that the effect of oxygen enrichment on the catalysts recovery efficiency was limited when the oxygen enrichment exceeded $5 \%$.

Key Words: Regenerator, CFD, Eulerian, Kinetic theory, Drag model, Hydrodynamics, Combustion. 


\section{Introduction}

Fluid Catalytic Cracking (FCC) process is one of the most important processes in petroleum refinery, which was paid considerable attention over the past 70 years [1]. FCC units play a pivotal role in petroleum refining industry that mainly converts low-value, high-boiling feedstock like gas oil into valuable products such as gasoline and middle distillates by using cracking catalyst $[2,3]$. The FCC zeolite catalyst particles belong to Group A particles which have mean size and density ranges of $\mathrm{d}<500 \mu \mathrm{m}, 1.4 \mathrm{~g} / \mathrm{cm}^{3}<\rho<4 \mathrm{~g} / \mathrm{cm}^{3}$, respectively [4]. During the FCC process, the FCC catalyst loses its reactivity due to the deposition of coke which is generated during the complicated chemical reactions. Since there are 40 to 50 tons of solid catalyst circulated in one FCC unit every minute [5], recycling the deactivated catalyst is critical for the entire process to reduce costs. Recovery of the catalyst reactivity by burning off the coke on the catalyst in the FCC regenerator is also important to maintain its cracking efficiency. Therefore, it is of great importance to understand the fluidized-bed flow properties and reactions inside the FCC regenerator to achieve high efficiency and low cost.

Fluidized bed technique is widely used in industrial processes, which has been comprehensively studied and optimized using numerical modeling. Both Lagrangian and Eulerian algorithms are used to simulate the gas-solid two phase flow, which consider the gas phase as a continuum [68]. However, Lagrangian algorithm solves the Newtonian equations of motion for each particle and takes into consideration of particle collisions effects. Particle collision laws are applied for the solid-solid collision based on the energy dissipation by means of restitution coefficient and friction $[9,10]$. Fluidization phenomena simulation by using Lagrangian algorithm has been reported in lab scale [11]. It is difficult to use Discrete Phase Model (DPM) to model industrial powder process [12]. Lagrangian model also requires more computational resources compared to an Eulerian model and most of the application are limited to big particles $(\mathrm{d}>500 \mu \mathrm{m})$ $[9,10,13]$. Gas and particles are all considered as continuums and fully interpenetrating in Eulerian algorithm. The interactions between two continuous phases are described by generalized Navier-Stokes equations with additional closure laws to describe particle-particle and particle-wall interactions. Kinetic theory of granular flow provides explicit closures for Geldart A particles, such as FCC catalyst, with both efficiency and accuracy [14-19]. 
The main task for FCC regenerator is to consume the coke (including carbon and hydrogen) on the catalyst surface through combustion and also to elevate the catalyst bulk temperature to ensure optimal conditions for cracking reactions. However, majority of the CFD studies of fluidized bed devices available in the literatures focused on isothermal process [20]. Due to the computational cost, the application of the fundamentals-oriented models, such as the EulerianEulerian multiphase models applying the kinetic theory of granular flow, for simulation of industrial-scale circulating fluidized bed furnaces has been small. [21] Improvements in numerical techniques and computing power have provided opportunities to advance CFD application on simulating the reactions in a fluidized bed. Lu et al. [22-24] studied the heat transfer and hydrodynamics in a fluidized bed using kinetic theory of granular flow without considering reactions. Due to the complexity of multiphase combustion process in fluidized bed which involves homogeneous and heterogeneous reaction process, only few literatures [25-27] considered CFD for combustion in fluidized bed while overlooking three dimensional effects. Adamczyk et al. [28-29] applied a dense discrete phase model to simulation circulating fluidized bed using ANSYS Fluent. For FCC process, only experiments, empirical and semi-empirical 1D and 2D models are reported in studying the reactions in FCC regenerator [30-34]. Therefore, applying the advanced CFD technique on the FCC catalyst regeneration process to optimize the design and operation is of great significance. And the CFD method is expected to substitute empirical models in future [20].

This paper employs Computational Fluid Dynamics (CFD) to simulate a commercial regenerator. Based on the multiphase Eulerian model with kinetic theory of granular flow, the air-catalyst two phase multi-species reacting flow inside the regenerator was modeled. The flow hydrodynamics was also obtained by using a modified drag model to calculate the gas-solid interaction drag force. Restitution coefficient 0.9 was applied to define the solid-solid collision forces [35]. A reaction model which includes homogeneous and heterogeneous combustion was developed to simulate the multiphase reactions, temperature and species distributions in the FCC regenerator. The simulation results are compared with the plant data. The effect of the important parameter, such as oxygen enrichment, on the flow and reactions has been investigated.

\section{CFD Model and Methodology}


The Euler-Euler approach, in which the two phases (gas and solid) are considered to be continuous and fully inter-penetrating, is employed. The kinetic theory of granular flow was applied in this simulation, with a Reynolds number of approximately $4 \times 10^{5}$. Gao et al. $[18,19]$ reported that the laminar viscous model was able to accurately predict flows in the same range of Reynolds number. Therefore, the laminar viscous model was applied in this study. Almuttahar et al. [36] also reported that even in the case of high density circulating fluidized bed, laminar model can give better prediction to the hydrodynamics compared to turbulence models. Chang, et al. [37] applied laminar model to calculate viscous force on an industrial turbulent fluidized bed reactor and validated the axial bed density profile with industrial data. Reaction and heat transfer models are needed in order to model the main function of FCC regenerator to recover catalyst cracking reactivity by burning off the coke on the catalysts. Finite-rate model was used for simulating the combustion. Heterogeneous reaction model with Gunn model [38] for interphase heat transfer were incorporated into the model. Finite-rate model combustion model was used for simulating chemical reactions. Both gas phase reaction and gas-solid interface reactions were defined. P1 radiation model was used for modeling the radiation heat transfer. The main reactions considered in this model were carbon oxidization, hydrogen combustion and $\mathrm{CO}$ combustion. The reaction rates were included into the model through User Defined Function (UDF) scripts based on the kinetics referred from literatures.

\subsection{Governing equations}

\subsubsection{Conservation of Mass}

Gas-phase continuity equation

$$
\partial(\alpha g \rho g) \partial t+\alpha g \rho g v g=m p g-m g p+S g
$$

Solid-phase continuity equation

$$
\partial(\alpha p \rho p) \partial t+\alpha p \rho p v p=m g p-m p g+S p
$$

where the first term is the time rate of change of gas phase or solid phase, the second term is the advection of the gas phase or solid phase. Each computational cell is shared by gas and solid phase with the total of solid and gas volume fraction is 1.

$$
\alpha p+\alpha g=1
$$

\subsubsection{Conservation of Momentum}


Gas-phase momentum equation

$$
\partial \partial t \alpha g \rho g v g+\partial \partial x j \alpha g \rho g v g v g=-\alpha g p+\tau g+\beta u g-u p+\rho g \alpha g g
$$

Solid-phase momentum equation

$$
\partial \partial t \alpha p \rho p v p+\partial \partial x j \alpha p \rho p v p v p=-\alpha p p+\tau p-\beta u g-u p+\rho p \alpha p g
$$

where the terms on the left hand of the equation are the time rate of change of gas or solid phase and advection term. On the right hand of the equation, body force (gravity, pressure), shear force term and phase interaction terms are considered. $\beta$ is the gas-solid interphase drag coefficient. The fluctuations that occur in the solid phase are modeled from the kinetic theory of gases modified to account for inelastic collisions between particles.

Solid-phase turbulent fluctuating energy equation

$$
32 \partial \alpha p \rho p \Theta \partial t+\nabla(\alpha p \rho p v p \Theta)=-p p I+\tau p: \nabla v p+\nabla \cdot k \Theta \nabla \Theta-\gamma \Theta+\varnothing g p
$$

Where $-p p I+\tau: \nabla v p$ is the generation of energy by the solid stress tensor, $k \Theta \nabla \Theta$ is the diffusion energy, $\gamma \Theta$ the collisional dissipation of energy, $\varnothing g p$ the energy exchange between the gas phase and the particle phase.

In order to close the governing relations, constitutive equations (7) to (17) are used in this model. Gas-phase stress tensor

$$
\tau g=\alpha g \mu g \nabla u g+\nabla u g T+\alpha g(\lambda g-23 \mu g) \nabla u g I
$$

Solid-phase stress tensor

$$
\tau p=\alpha p \mu p \nabla u p+\nabla u p T+\alpha p(\lambda p-23 \mu p) \nabla u p I
$$

Solid-phase pressure

$$
p p=\alpha p \rho p 1+2(1+e) \alpha p g O \Theta
$$

Radial distribution function

$$
g 0=1-\alpha p \alpha p, \max 13-1
$$

Granular temperature

$$
\Theta=13 u p^{\prime} u p^{\prime}
$$

Solids phase shear viscosity (Gidaspow kinetic theory) 


$$
\mu p=10 \rho p d p \pi \Theta 96(1+e) g 01+45(1+e) g 0 \alpha p 2+45 \alpha p 2 \rho p d p g O(1+e) \Theta \pi
$$

Solids phase shear viscosity (Syamlal-O'Brien kinetic theory)

$$
\mu p=\alpha p \rho p d p \pi \Theta 6(3-e) 1+25(1+e)(3 e-1) g 0 \alpha p 2+45 \alpha p 2 \rho p d p g O(1+e) \Theta \pi
$$

Solids bulk viscosity

$$
\lambda p=43 \alpha p \rho p \operatorname{dpg} O(1+e) \Theta \pi
$$

Diffusion coefficient (Gidaspow kinetic theory)

$$
\Gamma \Theta=150 \rho p d p \pi \Theta 384(1+e) g 01+65(1+e) g 0 \alpha p 2+2 \alpha p 2 \rho p d p g O(1+e) \Theta \pi
$$

Diffusion coefficient (Syamlal-O'Brien kinetic theory)

$$
\Gamma \Theta=15 \alpha p \rho p d p \pi \Theta 4(41-3321+e) 1+351+e 22 e-1 g 0 \alpha p+815 \pi(41-3321+e)(1+e) \alpha p g
$$

Collisional dissipation of energy fluctuation

$$
\gamma \Theta=12(1-e 2) g \text { Odp } л \rho р \alpha p 2 \Theta 3 / 2
$$

The transfer of the kinetic energy of random fluctuations in the particle velocity from the solid phase to the gas phase is:

$$
\varnothing g p=-3 K p g \Theta
$$

A modified drag model was used with considering the clustering phenomenon in both dense dilute phase and dilute phase. The influential cluster diameters in the dense phase and the dilute phase were determined in previous research [39]. The modified drag model is listed in Table 1.

\subsubsection{Conservation of Energy}

Gas-phase energy equation

$\partial \partial t \alpha g \rho g h g+\nabla \bullet \alpha g \rho g h g u g=\alpha g \partial P g \partial t+\tau g: \nabla u g-\nabla q g+S g+q=12(Q q g+m q g h q g-m g q h g q)$

Solid-phase energy equation $\partial \partial t \alpha p \rho p h p+\nabla \bullet \alpha p \rho p h p u p=\alpha p \partial P p \partial t+\tau p: \nabla u p-\nabla q p+S p+q=12(Q q p+m q p h q p-m p q h p q)$ 
where represents gas phase, represents solid phase, represent liquid phase, represents any other two phases except the calculated phase in each equation. is the specific enthalpy of the gas phase, is the heat flux, is a source term that includes sources of enthalpy (such as radiation), is the intensity of heat exchange between gas and solid or liquid phase. is the interphase enthalpy.

$$
Q q g=C q g(T q-T g)
$$

Cqg is the volumetric heat transfer coefficient between solid or liquid phase and gas phase, which related to the phase $q$ Nusselt number, $N u q$.

$$
C q g=6 \mathrm{Kgaqag} N u q d q 2
$$

$K g$ is the thermal conductivity of gas phase.

For Gunn heat transfer model [38], the

$$
\begin{gathered}
N u p=7-10 a g+5 a g 21+0.7 \operatorname{Rep} 0.2 \operatorname{Pr} 13+(1.33-2.4 a g+1.2 a g 2) \operatorname{Rep} 0.7 \operatorname{Pr} 13 \\
\operatorname{Pr}=c p g \mu g K g
\end{gathered}
$$

\section{P1 Radiation Model}

In FCC regenerator, another heat transfer form is radiation due to the combustion occurs inside with high temperature around $1000 \mathrm{~K}$. Therefore, thermal radiation should be considered. The radiation heat flux as function of incident radiation intensity in P1 model is:

$$
q r=-13(a+\sigma s)-C \sigma s \nabla G
$$

where $a$ is the absorption coefficient, $\sigma s$ is the scattering coefficient, $G$ is the incident radiation, $C$ is the linear-anisotropic phase function coefficient.

$$
-\nabla q r=a G-4 a n 2 \sigma T 4
$$

The expression for $-\nabla q r$ can be directly substitute into the energy equation to account for the heat sources due to the radiation.

\subsubsection{Conservation of Species}


Species transport equations are used to model the species which are involved in the chemical reactions. For each phase $\mathrm{k}$, predict the local mass fraction of each species, Yik, through the solution of a convection-diffusion equation for i species, when applied to multiphase mixture can be expressed in the following form:

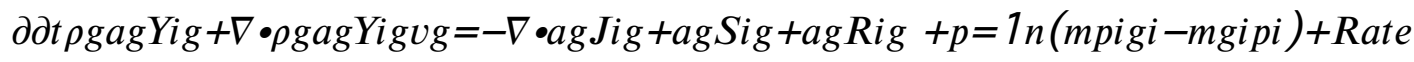

where Rig is the net rate of production of homogeneous species i by chemical reaction for gas phase. mpigi is the mass transfer source between species $\mathrm{i}$ and $\mathrm{j}$ from solid phase to gas phase. Rate is the heterogeneous reaction rate. agis the volume fraction for gas phase. Sig is the rate of creation by addition from the dispersed phase plus any user-defined sources.

In FCC regenerator, deposited coke on the solid catalyst surface reacts with gas phase species $\mathrm{O}_{2}$ and $\mathrm{CO}_{2}$. Such interphase chemical reactions are also known as heterogeneous reactions. The heterogeneous phase interaction reaction rates used for the reactions [43] are:

$$
\begin{gathered}
\text { Rate }=k i=1 \text { NRYiipVOFipMWi } * 1000 s t * 10-3 \mathrm{kmolm} 3-s \\
k=A(\text { TipTref }) b \exp (-E R \text { Tip })
\end{gathered}
$$

where, $Y i$ is $\mathrm{i}^{\text {th }}$ species mass fraction. $N R$ is the total number of reactants in a given inter-phase reaction. ip is the bulk density of phase ip. VOFip is the volume fraction of phase ip. $M W i$ is the molecular weight of the reactant species. st is the stoichiometric coefficient of reactant in the given reaction. $k$ is the rate constant. Tip is phase temperature. Tre $f$ is reference temperature. $A$ is pre-exponential factor, and $E$ is activation energy.

\subsection{Simulation code and solution method}

This simulation was using the commercial software package ANSYS Fluent ${ }^{\circledR}$. The Finite Volume Method (FVM) [44] was used to solve the partial differential equations by discretized the equations using an upwind differencing scheme. The Phase Coupled SIMPLE algorithm was applied to adjust the pressure and velocities after each iteration. The transient approach was used to solve this problem due to the real flow characteristics. UDF scripts were coupled into the main 
solver to calculate the flow and reactions. The drag coefficient between the gas phase and solid phase based on previous developed modified drag model was applied by using UDF scripts. The reaction rates for four reactions are based on the heterogeneous reaction rate, which were also written as UDF. Each simulation was performed over 1200 seconds until the reaction reached a steady state. The calculations were using High Performance Computer (HPC) cluster at Purdue University Northwest. Detailed simulation parameters are listed in Table 2

\section{Boundary and initial conditions}

\subsection{Computational domain}

The computational geometry of the regenerator being studied is shown in Figure 1 (a). The regenerator cylindrical vessel includes nine two-stage cyclones, two levels of air rings, two spent catalyst inlets, and two regenerated catalyst outlets. The regenerator start-up operation normal starts with charging a certain amount of clean catalyst at the bottom. Fluidization air is then injected into the catalyst bed to form a fluidized bed. The continuous operation process then starts to recycle the spent catalyst from the riser reactor. The spent catalyst with a certain amount of transport air is fed into the regenerator through the spent catalyst inlets located at the bottom of the geometry. Air is continuously injected into the regenerator through the upper and lower air ring distributors located in the bottom to fluidize the catalyst bed and combust the coke on the catalyst surface. The catalysts carried by the gas to the top are separated from the gas in the two-stage cyclones and recycled back into the catalyst bed. This two stage group cyclones are generally equipped in FCC regenerators with the outlet duct of first stage cyclone directly coupled to the inlet duct of the secondary stage cyclone as shown in Figure 2. This group cyclones has advantages of high and flexible handling capacity, high efficiency, high separation precision and relatively low cost. [45,46] The regenerated catalysts are removed from the regenerator through the regenerated catalyst outlets with high temperature and recovered reactivity. A total number of 2 million cells was used for this simulation. The details of the mesh is shown in Figure 1(b). Mesh independent study can be found in previous work [39].

\subsection{Operating conditions}

Typical operational boundary conditions for this particular FCC regenerator was applied to the developed CFD model as shown in Table 3. The amount of regenerated catalyst extracted from 
the regenerator is equal to the amount of spent catalyst input from the spent catalyst inlet. The walls were set as no-slip wall boundary conditions for both solid phase and gas phase. Each phase contains multiple species. According to the plant measurements, the catalyst used for this simulation contains 1 percent coke, with carbon count for $92 \%$ and the remaining $8 \%$ is hydrogen. The gas phase contains species $\mathrm{O}_{2}, \mathrm{~N}_{2}, \mathrm{CO}, \mathrm{CO}_{2}, \mathrm{H}_{2} \mathrm{O}$. In addition, the catalyst goes through the cyclone was defined $100 \%$ recycled back to the regenerators with all the species concentrations unchanged as shown in Figure 2, which was expressed by UDF. The simulation was conducted based on the initial startup condition.

\subsection{Reaction mechanisms}

The carbon and hydrogen combustion reactions were taken into consideration in this CFD model. The global reaction mechanisms, kinetics and heat generation are listed in Table 4. [47-49] The kinetic parameters for reaction1 (R1) and reaction 2 (R2) are obtained from the experimental work done by Kanervo et al. [47], in which reaction rates of combustion of coke on FCC solid catalyst particles to produce $\mathrm{CO}$ and $\mathrm{CO}_{2}$ in a reactor were measured. The kinetic parameters from the experimental work of hydrogen combustion in carbonaceous deposits on zeolite-type cracking catalysts reported by Wang et al. [48] was used for the hydrogen combustion. The kinetics for the CO combustion is adopted from the work by Dryer and Glassman [49]. This kinetics does not include the effects $\mathrm{CO}$ combustion promoter which is used in the actual regenerator operations.

\section{Results and discussions}

\subsection{Simulation results}

The model has been validated by plant data under typical operation condition as shown in Table 5. The catalyst circulation flow rate through cyclones were predicted by the CFD model, which agrees with the real measurement data monitored in plant. Pressure drop between two locations at different heights (one in the dense zone and the other in the dilute zone) inside the regenerator is measured during the regenerator operation. The error of the pressure drop calculated by the model relative to the average of the pressure drop range of the actual regenerator is $4 \%$. Temperature field and the major species volume fractions has also been compared with plant data. The relative errors between the temperature predicted by the model and measurements in 
both dense zone and dilute zone are within 1\%. The relative error of $\mathrm{CO}$ is high. However, it should be noted that the $\mathrm{CO}$ concentration at the cyclone inlets is extremely low. This high relative error of $\mathrm{CO}$ concentration is due to the fact that, the kinetics for the $\mathrm{CO}$ combustion used in the model does not take into account any $\mathrm{CO}$ combustion promoters. In the real operations, $\mathrm{CO}$ combustion promoters are added into the catalyst bed to promote $\mathrm{CO}$ combustion in the dense bed. It is desired to have as much $\mathrm{CO}$ as possible burned inside the dense bed thus the amount of $\mathrm{CO}$ that goes $\mathrm{CO}$ combustion in the dilute zone can be minimized. More detailed validation process can be found in previous work [39].

In this simulation, due to the transient flow properties, a transient simulation processes was applied to simulate fluid flow and combustion reactions which was started from initial startup condition to a quasi-steady state. The fluidization process of the solid FCC catalyst in the regenerator is shown in Figure 3.

Figure 3 shows that at the startup conditions, where the catalyst bed is resting at the bottom of the FCC regenerator. With the input of air from the air rings, the fluidization phenomenon took place. The catalysts were firstly fluidized by the air with a high fluidized bed due to the initial high accumulated momentum. After the flow reached a quasi-steady state after 100s, it shows similar flow patterns but different flow property values at specific locations over time. The catalyst solid volume fraction contour shows that there are four zones along the regenerator height: dense zone, sub-dense zone, dilute zone and sub-dilute zone. The sub-dense zone is also called the fluidized bed; while in the dense zone, the solid catalyst is difficult to be fluidized due to the geometry effect. Dilute zone has low catalyst concentration which is between the fluidized bed and cyclones. The region above the cyclones almost has no catalyst concentration which called sub-dilute zone as shown in Figure 3.

The fluidized bed combustion process also occurs with the development of fluid flow. The transient process of temperature evolution at five different normalized regenerator heights were plotted in Figure 4. The temperature value is the mass weighted average temperature on the cross sectional area.

Figure 4 shows the transient temperature evolution process inside a FCC regenerator. It is shown that the combustion occurs immediately after the spent catalysts are transported into the 
regenerator. The gas temperature evolution inside the FCC reheating furnace can be divided into three stages. The gas temperature increases linearly at the first 200s. Then, the rate of temperature evolution increases dramatically from 300 s to $600 \mathrm{~s}$. After $600 \mathrm{~s}$, the temperature increase rate reduces and reaches a steady state after 1000 seconds. In addition, among the five different levels, the level $\mathrm{h} / \mathrm{H}=0.15$ and $\mathrm{h} / \mathrm{H}=0.24$ are in the fluidized bed. The temperature evolution profiles at different heights indicate that the temperature in the fluidized bed is lower than temperature in the dilute phase and the maximum difference is approximately $20 \mathrm{~K}$. This temperature difference indicates a CO combustion occurred above the fluidized bed. At 1260s, after the flow and reaction reached quasi-steady state, the mass weighted average catalyst volume fraction and the temperature profiles along the FCC regenerator height were plotted in Figure 5.

Figure 5 shows that the average temperature in the fluidized bed is lower than that in the dilute zone. The transition region between the fluidized bed and the dilute zone raises the gas temperature due to the $\mathrm{CO}$ combustion. The spikes at the top region $(\mathrm{h} / \mathrm{H}=0.89)$ on both the averaged solid volume fraction and temperature profiles are due to the effect of cyclone geometry. The catalyst accumulates on the cyclone top surface while the high temperature flue gas emits from the cyclones.

Figure 6 shows the mass weighted average mass fractions profiles of species $\mathrm{C}<\mathrm{s}>$ and $\mathrm{H}_{2}$ in the solid catalyst along the regenerator height after the flow reaching the quasi-steady state. It indicates that the mass fraction of $\mathrm{C}<\mathrm{s}>$ and $\mathrm{H}_{2}$ in the catalyst at the regenerated catalyst outlet are $0.09 \%$ and $0.0015 \%$, respectively. By comparing to the original content $0.92 \%$ and $0.08 \%$, the reduction rate for $\mathrm{C}<\mathrm{s}>$ and $\mathrm{H}_{2}$ after combustion are $90 \%$ and $98 \%$, respectively. The $\mathrm{C}<\mathrm{s}>$ and $\mathrm{H}_{2}$ on the catalysts are further reduced in the dilute zone which increases the gas temperature at the dilute zone. The mass weighted average species concentrations in the gas phase along the regenerator height after reaction reached steady state are shown in Figure 7.

According to Figure 7, $\mathrm{CO}_{2}, \mathrm{H}_{2} \mathrm{O}$ and $\mathrm{O}_{2}$ are the major species, while the $\mathrm{CO}$ concentration is approximately zero. Along the regenerator height, the $\mathrm{CO}_{2}$ mass fraction increases above the fluidized bed. $\mathrm{O}_{2}$ mass fraction decreases greatly above the lower air ring, and further deceases 
to a small percentage above the fluidized bed. Due to the fast hydrogen combustion, the $\mathrm{H}_{2} \mathrm{O}$ mass fraction increases above the fluidized bed and remain stable below the cyclone.

\subsection{Effect of oxygen enrichment}

The ultimate goal for optimizing the existing FCC regenerator is to improve the FCC catalyst reactivity. Increasing the coke reduction without damaging the cyclone structure and catalyst itself by high temperature are the basic criteria for optimization. The optimal catalyst temperature in the dense is approximately $1000 \mathrm{~K}$. The simulation on FCC regenerator under the typical operating condition indicates that the coke reduction efficiency can be further improved. There are several parameters can be adjusted to improve the coke reduction: air flow rate, oxygen enrichment, geometry change. Oxygen enrichment is a technique that widely applied in the industrial furnace to improve combustion efficiency. Oxygen enrichment technique has been applied on current FCC regenerator operation process to improve the recovery of catalyst reactivity. Therefore, the effect of oxygen enrichment on the catalyst reactivity recovery process needs to be investigated based on the validated CFD model. The effect of 5\% and 10\% oxygen enrichment on the reaction inside the FCC regenerator has been studied. The effect of oxygen enrichment on the mass weighted average temperature field inside the FCC regenerator is shown in Figure 8.

According to Figure 8, 5\% oxygen enrichment would increase approximately $6 \mathrm{~K}$ in both the fluidized bed and the dilute zone along the FCC regenerator height. When further increase the oxygen enrichments to $10 \%$, the average temperature increased approximately $2 \mathrm{~K}$ in the dilute zone, which indicates that the combustion of the carbon and hydrogen in the solid phase reached a limit as shown in Figure 9.

According to Figure 9, with the increasing of oxygen enrichment, the mass weighted average carbon and hydrogen mass fractions in the fluidized bed decrease, which indicates an improvement in the reduction rates. The reduction rate of $\mathrm{C}<\mathrm{s}>$ increases from $90 \%$ to $94.5 \%$ and the $\mathrm{H}_{2}$ reduction rate increases from $98 \%$ to $99 \%$ when the oxygen enrichment is $5 \%$. However, after oxygen enrichment exceeds $5 \%$, the effect of oxygen enrichment on improving 
carbon and hydrogen reactions is limited. The limitation is also indicated by the mass weighted average gas species plots in Figure 10.

According to Figure 10, with the increasing of oxygen enrichment, the $\mathrm{CO}_{2}$ mass fraction increased in both fluidized bed and the dilute zone. The oxygen penetrates into in the bottom packed bed and increases the $\mathrm{CO}_{2}$ mass fraction significantly. However, the $\mathrm{CO}_{2}$ mass fraction stabilizes in the dilute phase when the oxygen enrichment exceeds $5 \%$. Due to the fast reaction rate of hydrogen combustion, the oxygen enrichment has limited effect on the species $\mathrm{H}_{2} \mathrm{O}$ distribution. It can be seen that with the increasing of oxygen enrichment, the mass fraction of $\mathrm{H}_{2} \mathrm{O}$ increases at the normalized height around 0.3 where the transition between fluidized bed and dilute phase occurs. However, the $\mathrm{H}_{2} \mathrm{O}$ mass fraction in the dilute zone keeps constant, which indicates that the hydrogen combustion occurred fast and oxygen enrichment effect is limited.

\section{Conclusions}

A three-dimensional multi-phase, multi-species reacting flow computational fluid dynamics (CFD) model has been established to simulate the flow characteristics and chemical reactions inside an FCC regenerator. The multiphase Eulerian model with kinetic theory of granular flow is employed. A modified drag model is used to calculate the drag force during solid catalyst fluidization process. Heterogeneous reaction model was employed where interphase reactions are considered. The finite-rate combustion model was used which use Arrhenius expressions. The developed CFD model was validated by using the plant data. This CFD model is able to predict the flow field, temperature distribution and species concentrations. The transient flow characteristics and the inter-phase reactions were studied. The effect of oxygen enrichment on the catalyst reactivity recovery was investigated, and the results show that coke reduction rate can be improved from $90 \%$ to $94.5 \%$ with $5 \%$ oxygen enrichment. The effect of oxygen enrichment is limited when it exceeds 5\%. This simulation did not consider the CO combustion promoters, which could introduce errors on the CO concentration.

\section{Acknowledgments}


The authors would like to thank BP Refining and Logistics Technology for providing funding for this project and Center for Innovation through Visualization and Simulation for providing all the resources required for this work.

This research was partially supported by U.S. Department of Energy Grant DE-NA000741 under the administration of the National Nuclear Security Administration.

\section{Nomenclatures}

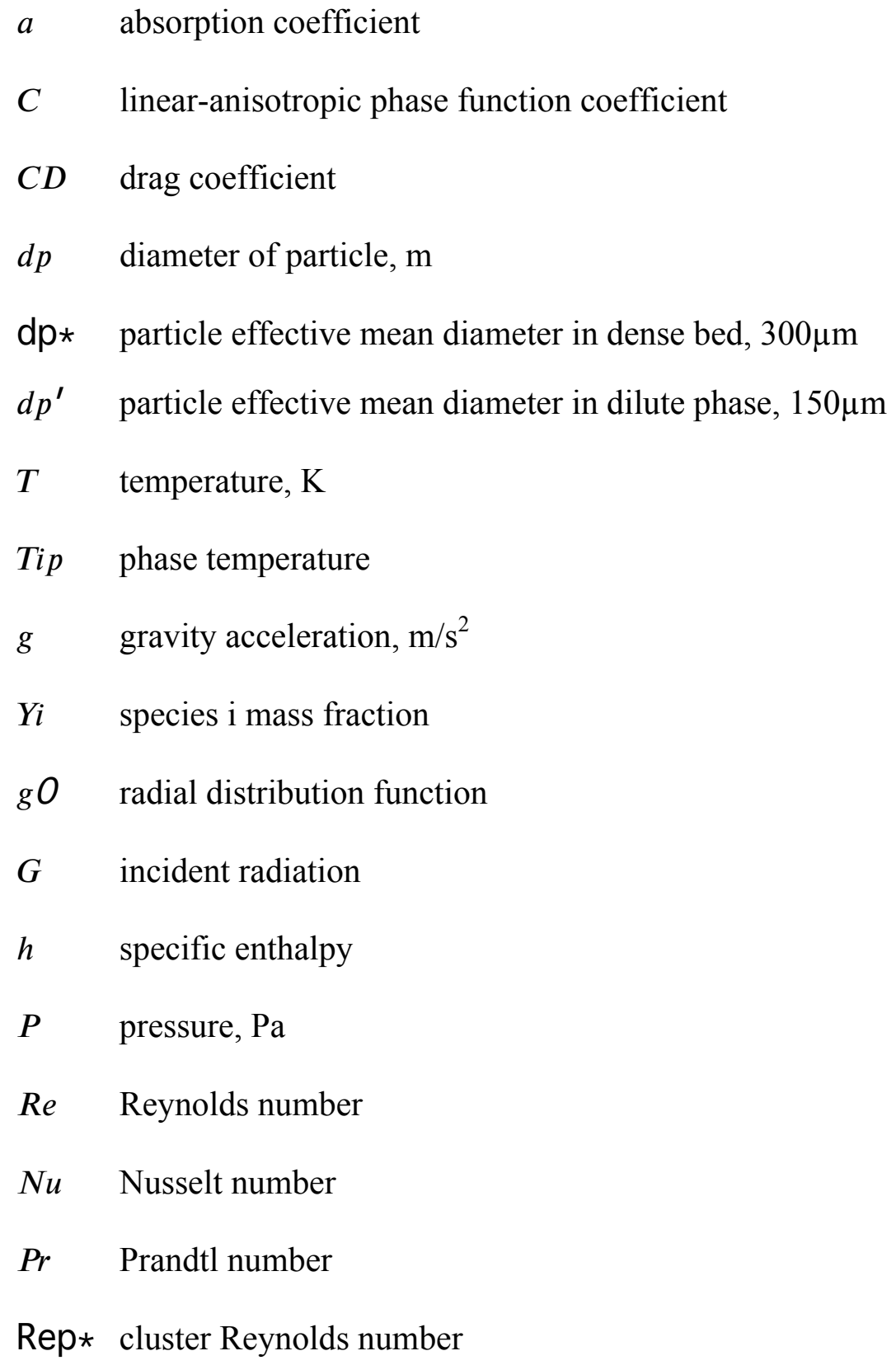


$t \quad$ time, $\mathrm{s}$

$u \quad$ velocity, $\mathrm{m} / \mathrm{s}$

ip bulk density of phase i

VOFip volumetric fraction of phase ip

$M W i$ molecular weight of species i

st stoichiometric coefficient of reactants

Tref reference temperature $(298 \mathrm{~K})$

the heat flux

source term that includes sources of enthalpy

the intensity of heat exchange between gas and solid or liquid phase

the interphase enthalpy

$K g$ the thermal conductivity of gas phase

$v g \quad$ the velocity of phase $g$

$v g \quad$ the velocity of phase $\mathrm{p}$

mpg the mass transfer from $\mathrm{p}$ phase to $\mathrm{g}$ phase

$S q \quad$ the source term

ug superficial gas velocity, $\mathrm{m} / \mathrm{s}$

up superficial particle velocity, $\mathrm{m} / \mathrm{s}$

I unit stress tensor

Greek letters

$\alpha \quad$ volume fraction

$\beta \quad$ inter-phase momentum exchange coefficient, $\mathrm{kg} / \mathrm{m}^{3}-\mathrm{s}$

$\gamma$ collisional dissipation of energy fluctuation, $\mathrm{kg}-\mathrm{s}^{3} / \mathrm{m}$ 
$\Gamma$ dil, dilute diffusion coefficient for energy fluctuation, $\mathrm{kg}-\mathrm{s} / \mathrm{m}$

$\Gamma \quad$ diffusion coefficient for the energy fluctuation, $\mathrm{kg}-\mathrm{s} / \mathrm{m}$

$\Theta \quad$ granular temperature, $\mathrm{m}^{2} / \mathrm{s}^{2}$

up particle phase shear viscosity, Pa-s

$\mu g \quad$ gas phase shear viscosity, Pa-s

$\lambda p \quad$ solid bulk viscosity, Pa-s

$\lambda g \quad$ gas bulk viscosity, $\mathrm{Pa}-\mathrm{s}$

$\rho$ density, $\mathrm{kg} / \mathrm{m}^{3}$

$\tau \quad$ stress tensor, $\mathrm{Pa}$

$e \quad$ the coefficient of restitution, 0.9

os $\quad$ scattering coefficient

$k \quad$ reaction rate constant

Superscripts and Subscripts

$i, j, k \quad$ direction coordinate

$g \quad$ gas phase

$\max$ maximum

$p \quad$ particle phase

$N R$ total number of reactants

\section{References}

1. J.L. Fernandes, C.I.C. Pinheiro, N.M.C. Oliverira, J. Inverno, F.R. Ribeiro, Model Development and Validation of an Industrial UOP Fluid Catalytic Cracking Unit with a High-Efficiency Regenerator, Ind. Eng. Chem. Res., 47(2008) 850-866.

2. I. Han, C.B. Chung, Dynamic modeling and simulation of a fluidized catalytic cracking process. Part I: Process modelling, Chemical Engineering Science, 56 (2001) 1951-1971.

3. H. Lu, D. Gidaspow, Hydrodynamics of binary fluidization in a riser: CFD Simulation using granular temperatures, Chemical Engineering Science, 58(2003) 3777-3792.

4. D. Geldart, Types of Gas Fluidization, Powder Technology, 7(1973) 285-292. 
5. F. Shaffer, B. Gopalan, R.W. Breault, R. Cocco, S.B.R. Karri, R. Hays, T. Knowlton, High speed imaging of particle flow fields in CFB riser, Powder Technology, 242(2013) 86-99.

6. S. Wang, H. Lu, X. Li, L. Yu, J. Ding, Y. Zhao, CFD simulations of bubbling beds of rough spheres, Chemical Engineering Science, 58(2008) 5653-5662.

7. M.J.V. Goldschmidt, J.A.M. Kuipers, W.P.M. van Swaaij, Hydrodynamic modeling of dense gas-fluidized beds using the kinetic theory of granular flow: effect of coefficient of restitution on bed dynamics, Chemical Engineering Science, 56(2001) 571-578.

8. M.J.V. Goldschmidt, J.A.M. Kuipers, R. Beetstra, Hydrodynamic modeling of dense gasfluidized beds: comparison and validation of 3D discrete particle and continuum models, Powder Technology, 142(2004) 23-47.

9. B.P.B. Hoomans, J.A.M. Kuipers, W.J. Briels, W.P.M. van Swaaij, Discrete particle simulation of bubble and slug formation in a two-dimensional gas-fluidized bed, Chemical Engineering Science, 51(1996)99-108.

10. B.H. Xu, A.B. Yu, Numerical simulation of the gas-solid flow in a fluidized bed by combining discrete particle method with computational fluid dynamics, Chemical Engineering Science, 52(1997) 2785-2908.

11. Y. Tsuji, T. Tanaka and T. Ishida, Lagrangian numerical simulation of plug flow of cohesionless particles in a horizontal pipe, Powder Technology, 71(1992) 239-250.

12. M. Sakai, H. Takahashi, C.C. Pain, J.P. Latham, J. Xiang, Study on a large-scale discrete element model for fine particles in fluidized bed, Advanced Powder Technology, 23(2012) 673-681.

13. Y. Tsuji, T. Kawaguchi and T. Tanaka, Discrete particle simulation of two-dimensional fluidized bed, Powder Technology, 77(1933) 79-87.

14. X. Lan, C. Xu, G. Wang, L. Wu, J. Gao, CFD modeling of gas-solid flow and cracking reaction in two-stage riser FCC reactors, Chemical Engineering Science, 64(2009) 38473858.

15. S. H. Hosseini, R. Rahimi, M. Zivdar, A. Samimi, CFD Simulation of gas-solid bubbling fluidized bed containing FCC particles, Korean J. Chem. Eng., 26(5) (2009) 1405-1413.

16. S.H. Hosseini, G. Ahmadi, R. Rahimi, M. Zivdar, M.N. Esfahany, CFD studies of solids hold-up distribution and circulation patterns in gas-solid fluidized beds, Powder technology, 200(2010) 202-215.

17. T. Mckeen, T. Pugsley, Simulation and experiment validation of a freely bubbling bed of FCC catalyst, Powder Technology, 129(2003) 139-152.

18. J. Gao, X. Lan, Y. Fan, J. Chang, G. Wang, C. Lu, C. Xu, Hydrodynamics of gas-solid fluidized bed of disparately sized binary particles, Chemical Engineering Science, 64(2009) 4302-4316.

19. J. Gao, X. Lan, Y. Fan, J. Chang, G. Wang, C. Lu and C. Xu. CFD Modeling and validation of the turbulent fluidized bed of FCC particles, Particle technology and fluidization, 55(7) (2009) 1680-1694.

20. R.I. Singh, A. Brink, M. Hupa, CFD modeling to study fluidized bed combustion and gasification, Applied Thermal Engineering, 52(2013) 585-614.

21. M.H. Bordbar, K. Myohanen, T, Hyppanen, Coupling of a radiative heat transfer model and a three-dimensional combustion model for a circulating fluidized bed furnace, Applied Thermal Engineering 76(2015) 344-356. 
22. Y. Lu, T. Zhang, X. Dong, Numerical analysis of heat transfer and solid volume fraction profiles around a horizontal tube immersed in a supercritical water fluidized bed, Applied Thermal Engineering, 93(2016) 200-213.

23. N.H. Dong, L.M. Armstrong, S. Gu, K.H. Luo, Effect of tube shape on the hydrodynamics and tube to bed heat transfer in fluidized bed, Applied Thermal Engineering, 60(2013) 472-479.

24. M. Fattahi, et al., CFD simulation of transient gas to particle heat transfer for fluidized and spouted regimes, Applied Thermal Engineering, (2015), http://dx.doi.org/10.1016/j.applthermaleng.2015.05.071.

25. W. Zhou, C. Zhao, L. Duan, D. Liu, X. Chen, CFD modeling of oxy-coal combustion in circulating fluidized bed, International Journal of Greenhouse Gas Control, 5(2011) 1489-1497.

26. W. Zhou, C. Zhao, L. Duan, D. Liu, X. Chen, Numerical Simulation on hydrodynamics and combustion in a circulating fluidized bed under $\mathrm{O}_{2} / \mathrm{CO}_{2}$ and air atmospheres, Proceeding of 20th international conference on Fluidized Bed Combustion, (2009) 839844.

27. M.H. Bordbar, K. Myohanen, T. Hyppanen, Coupling of a radiative heat transfer and a three-dimensional combustion model for a circulating fluidized bed furnace, Applied Thermal Engineering, 76(2015) 334-356.

28. W.P. Adamczyk, P. Kozolub, A. Klimanek, R.A. Bialecki, M. Andrzejczyk, M. Klajny, Numerical simulations of the industrial circulating fluidized bed boiler under air- and oxy-fuel combustion, Applied Thermal Engineering 87 (2015) 127-136.

29. W.P. Adamczyk, G. Wecel, M. Klajny, P. kozolub, A. Klimanek, R.A. Bialecki, Modeling of particle transport and combustion phenomena in a large-scale circulating fluidized bed boiler using a hybrid Euler-Lagrange approach, Particuology 16 (2014) 2940.

30. D. Bai, J.X. Zhu, Y. Jin, Z. Yu, Simulation of FCC catalyst regeneration in a riser regenerator, Chemical Engineering Journal, 71(1988) 97-109.

31. V.D. Dimitriadis, A.A. Lappas, I.A. Vasalos, Kinetics of combustion of carbon in carbonaceous deposits on zeolite catalysts for fluid catalytic cracking units (FCCU). Comparison between Pt and non Pt-containing catalysts, Fuel, 77(12)(1998) 1377-1383.

32. O. Faltsi-Saravelou, I.A. Vasalos, G. Dimogiorgas, FbSim: A model for fluidized bed simulation II. Simulation of an industrial fluidized catalytic cracking regenerator, Computers Chem. Engng, 15(9)(1991) 647-656.

33. S.V. Sotirchos, E. Mon, N.R. Amundson, Combustion of coke deposits in a catalyst pellet, Chemical Engineering Science, 38(1)(1983) 55-68.

34. L. Lee, S. Yu, C. Cheng, Fluidized-bed catalyst cracking regenerator modeling and analysis, The Chemical Engineering Journal, 40(1989) 71-82.

35. K. Hong, S. Chen, W. Wang, J. Li, Fine-grid two-fluid modeling of fluidization of Geldart A particles, Powder Technology 296 (2016) 2-16.

36. A. Almuttahar, F. Taghipour, Computational fluid dynamics of high density circulating fluidized bed riser: Study of modeling parameters, Powder Technology, 185(2008) 11-23.

37. J. Chang, et al., Hydrodynamic modeling of an industrial turbulent fluidized bed reactor with FCC particles, Powder Technol. (2016), http://dx.doi.org/10.1016/j.powtec.2016.04.048. 
38. D.J. Gunn, Transfer of Heat or Mass to Particles in Fixed and Fluidized Bed, Int. J. Heat Mass Transfer, 21(1978) 467-476.

39. G. Tang, A. Silaen, B. Wu, C.Q. Zhou, D. Agnello-Dean, J. Wilson, Q. Meng, S. Khanna, Numerical simulation of an industrial fluid catalytic cracking Regenerator, Journal of Thermal Science and Engineering Application, 7(2). 021012, 2015, doi:10.1115/1.4029209.

40. S. Ergun, Fluid flow through packed columns, Chem Eng Progr, 48(1952) 89-94.

41. C.Y. Wen, Y.H. Yu, Mechanics of fluidization, Chemical Engineering Progress Symposium Series, 62(1966) 100-111.

42. L. Schiller, A. Naumann, A drag coefficient correlation, VDI Zeits 77(1933) 318-320.

43. FLUENT 15.0, User's Guide, FLUENT, Inc.

44. H.K. Versteeg, W. Malalasekera, An introduction to Computational Fluid Dynamics, the finite volume method, Prentice-Hall, Essex, UK, 2007.

45. C. Huang, W. Lv, J. Wang, J. Wang, H. Wang, Uniform distribution design and performance evaluation for UU-type parallel mini-hydrocyclones, Separation and Purification Technology 125 (2014) 194-201.

46. C. Chen, H. Wang, G. Gan, J. Wang, C. Huang, Pressure drop and flow distribution in a group of parallel hydrocyclones: Z-Z-type arrangement, Separation and Purification Technology 108 (2013) 15-27.

47. J.M. Kanervo, A.O. Krause, J.R. Aittama, P.H. Hagelberg, K.J.T. Lipiainen, I.H. Eilos, J.s. Hiltunen, V.M. Niemei, Kinetics of regeneration of a cracking catalyst derived from TPO measurements, Chemical Engineering Science, 56(2001) 1221-1227.

48. G. Wang, S. Lin, W. Mo, C. Peng, G. Yang, Kinetics of Combustion of Carbon and Hydrogen in Carbonaceous Deposits on Zeolite-Type Cracking Catalyst, Industrial \& Engineering Chemistry Process Design and Development, 25(1986) 626-630.

49. F.L. Dryer, I. Glassman, High-temperature oxidation of $\mathrm{CO}$ and $\mathrm{CH}_{4}, 14$ th Symposium International on Combustion, Combustion Institute, (1973) p. 987. 


\section{List of Tables}

Table 1 Modified drag coefficient with zone classification

Table 2 Simulation parameters

Table 3 Boundary Conditions

Table 4 Reaction mechanisms and kinetics

Table 5 Relative errors of the simulation results when compared with plant data 
Table 1 Modified drag coefficient with zone classification

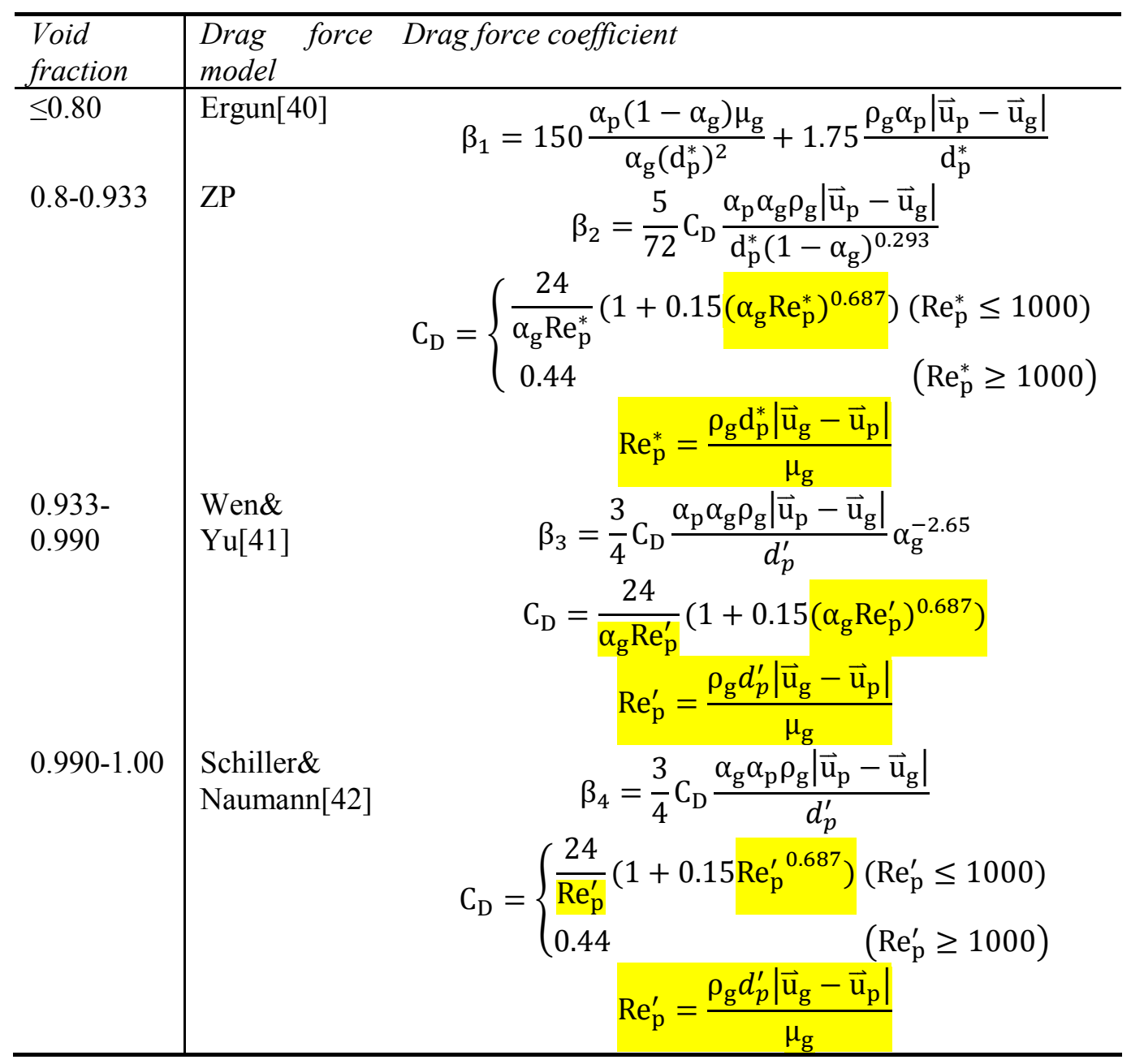


Table 2 Simulation parameters

\begin{tabular}{|l|l|}
\hline Parameters & Value and methods \\
\hline Gas-solid two phase flow model & $\begin{array}{l}\text { Eulerian-Eulerian model with kinetic theory } \\
\text { (granular) }\end{array}$ \\
\hline Solver & Pressure based and transient \\
\hline Flow type & Laminar \\
\hline Wall boundary condition & No slip \\
\hline Time step used & $0.01 \mathrm{~s}$ \\
\hline Pressure velocity coupling scheme & Phase Coupled SIMPLE \\
\hline Under-relaxation Factors & $\begin{array}{l}\text { Pressure } 0.3, \text { momentum } 0.7, \text { volume fraction } \\
0.5, \text { granular temperature } 0.2 \text {. Species } 0.6\end{array}$ \\
\hline $\begin{array}{l}\text { Maximum solid packing volume } \\
\text { fraction }\end{array}$ & 0.6 \\
\hline Spatial Discretizations & $\begin{array}{l}\text { Gradient: Green-Gauss Cell Based } \\
\text { Momentum, energy, species: second order } \\
\text { upwind, } \\
\text { Volume fraction: first order upwind. }\end{array}$ \\
\hline Gas mixture density & Incompressible ideal gas law. \\
\hline Superficial velocity & $0.6 \sim 0.7 \mathrm{~m} / \mathrm{s}$ \\
\hline Absorption coefficient & $\begin{array}{l}\text { Gray WSGG with domain based mean beam } \\
\text { length }\end{array}$ \\
\hline Scattering coefficient & 0 \\
\hline Solid mixture density & Volume weighted mixing law \\
\hline Catalyst particle density & $1440 \mathrm{~kg} / \mathrm{m}^{3}$ \\
\hline Catalyst particle mean diameter & $75 \mu \mathrm{m}$ \\
\hline Solid particle absorption efficiency & 0.9 \\
\hline Solid particle scattering efficiency & 0.1 \\
\hline
\end{tabular}


Numerical Simulation and Optimization of an Industrial Fluid Catalytic Cracking Regenerator

Table 3 Boundary Conditions

\begin{tabular}{ccccc}
\hline & $\begin{array}{c}\text { Spent } \\
\text { Catalyst Inlet }\end{array}$ & $\begin{array}{c}\text { Upper } \\
\text { Air Ring }\end{array}$ & $\begin{array}{c}\text { Lower Air } \\
\text { Ring }\end{array}$ & $\begin{array}{c}\text { Regenerated } \\
\text { Catalyst Outlet }\end{array}$ \\
\hline $\begin{array}{c}\text { Velocity }(\mathrm{m} / \mathrm{s}) \\
\text { Gas volume } \\
\text { fraction }\end{array}$ & 5.6 & 12.9 & 15.7 & 1.1 \\
$\begin{array}{c}\text { Solid volume } \\
\text { fraction }\end{array}$ & 0.05 & 1 & 1 & 0 \\
\hline
\end{tabular}


Table 4 Reaction mechanisms and kinetics

\begin{tabular}{lllll}
\hline & Reactions & $\begin{array}{l}\text { Heat of reaction } \\
(\mathrm{kJ} / \mathrm{mol})\end{array}$ & Pre-exponential factor & $\begin{array}{l}\text { Activation } \\
\text { Energy }(\mathrm{J} / \mathrm{mol})\end{array}$ \\
\hline $\mathrm{R} 1$ & $\mathrm{C}+1 / 2 \mathrm{O}_{2} \rightarrow \mathrm{CO}$ & 118 & $0.155 \times 10^{8} \mathrm{~s}^{-1} \cdot \mathrm{atm}^{-1}$ & 159,000 \\
$\mathrm{R} 2$ & $\mathrm{C}+\mathrm{O}_{2} \rightarrow \mathrm{CO}_{2}$ & 403 & $0.376 \times 10^{8} \mathrm{~s}^{-1} \cdot \mathrm{atm}^{-1}$ & 110,000 \\
$\mathrm{R} 3$ & $\mathrm{CO}+1 / 2 \mathrm{O}_{2} \rightarrow \mathrm{CO}_{2}$ & 283 & $0.149 \times 10^{12} \mathrm{~kg}^{-1} \cdot \mathrm{m}^{-3} \cdot \mathrm{atm}^{-2}$ & 212,000 \\
$\mathrm{R} 4$ & $\mathrm{H}_{2}+1 / 2 \mathrm{O}_{2} \rightarrow \mathrm{H}_{2} \mathrm{O}$ & 600 & $3.3 \times 10^{07} \mathrm{~kg}^{-1} \cdot \mathrm{s}^{-1} \cdot \mathrm{atm}^{-1}$ & 157,700 \\
\hline
\end{tabular}


Table 5 Relative errors of the simulation results when compared with plant data

\begin{tabular}{|c|c|}
\hline Parameters & Relative error \\
\hline Catalyst circulation & $2.74 \%$ \\
\hline$\Delta \mathrm{P}\left(\mathrm{inH}_{2} \mathrm{O}\right)$ & $4.0 \%$ \\
\hline Dense zone temperature & $0.50 \%$ \\
\hline Dilute zone temperature & $0.29 \%$ \\
\hline $\mathrm{C}$ reduction rate $(\%)$ & $1.7 \%$ \\
\hline \multicolumn{2}{|l|}{ Volume fraction at outlets: } \\
\hline $\mathrm{CO}(\mathrm{ppm})$ & $8881.8 \%$ \\
\hline $\mathrm{CO}_{2}$ & $1.2 \%$ \\
\hline $\mathrm{O}_{2}\left(\mathrm{vol}^{2} \%\right)$ & $14.9 \%$ \\
\hline
\end{tabular}




\section{List of Figures}

Figure 1 (a).Computational domain with boundaries, (b). mesh

Figure 2 Cyclone boundary conditions

Figure 3 Solid volume fraction profiles changing with time

Figure 4 Gas temperature evolution at different levels along the regenerator height

Figure 5 Mass weighted average solid volume fraction and gas temperature along regenerator height

Figure 6 Mass weighted average species mass fraction in solid phase along regenerator height Figure 7 Mass weighted average species mass fractions in gas phase along regenerator height Figure 8 Effect of oxygen enrichments on average gas temperatures along regenerator height

Figure 9 Effect of oxygen enrichments on species $\mathrm{C}<\mathrm{s}>$ and $\mathrm{H}_{2}$ in the solid phase along the regenerator height

Figure 10 Effect of oxygen enrichments on gas phase species $\mathrm{CO}_{2}$ and $\mathrm{H}_{2} \mathrm{O}$ along the regenerator height 


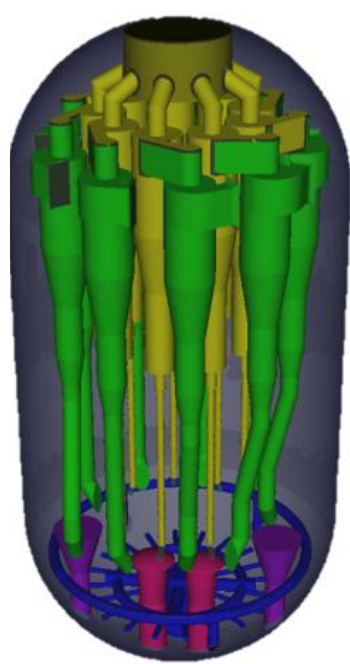

3D in Paraview

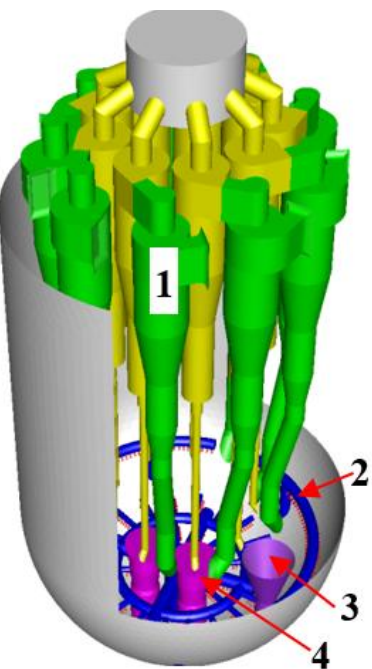

View in Fluent

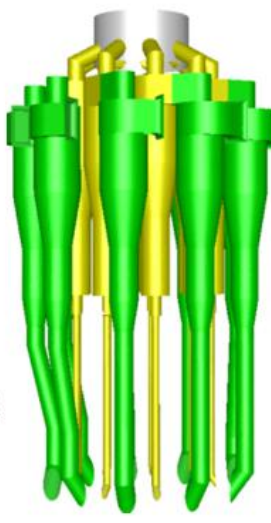

1. two-stagecyclones

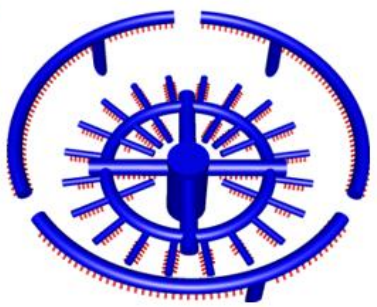

2 Upper and

Lower air rings

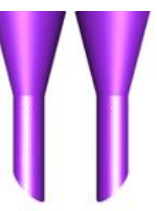

3 Regenerated catalyst outlet

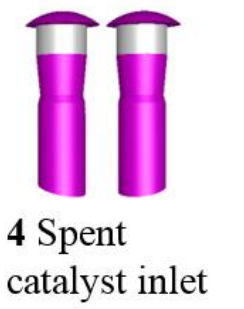

(a)

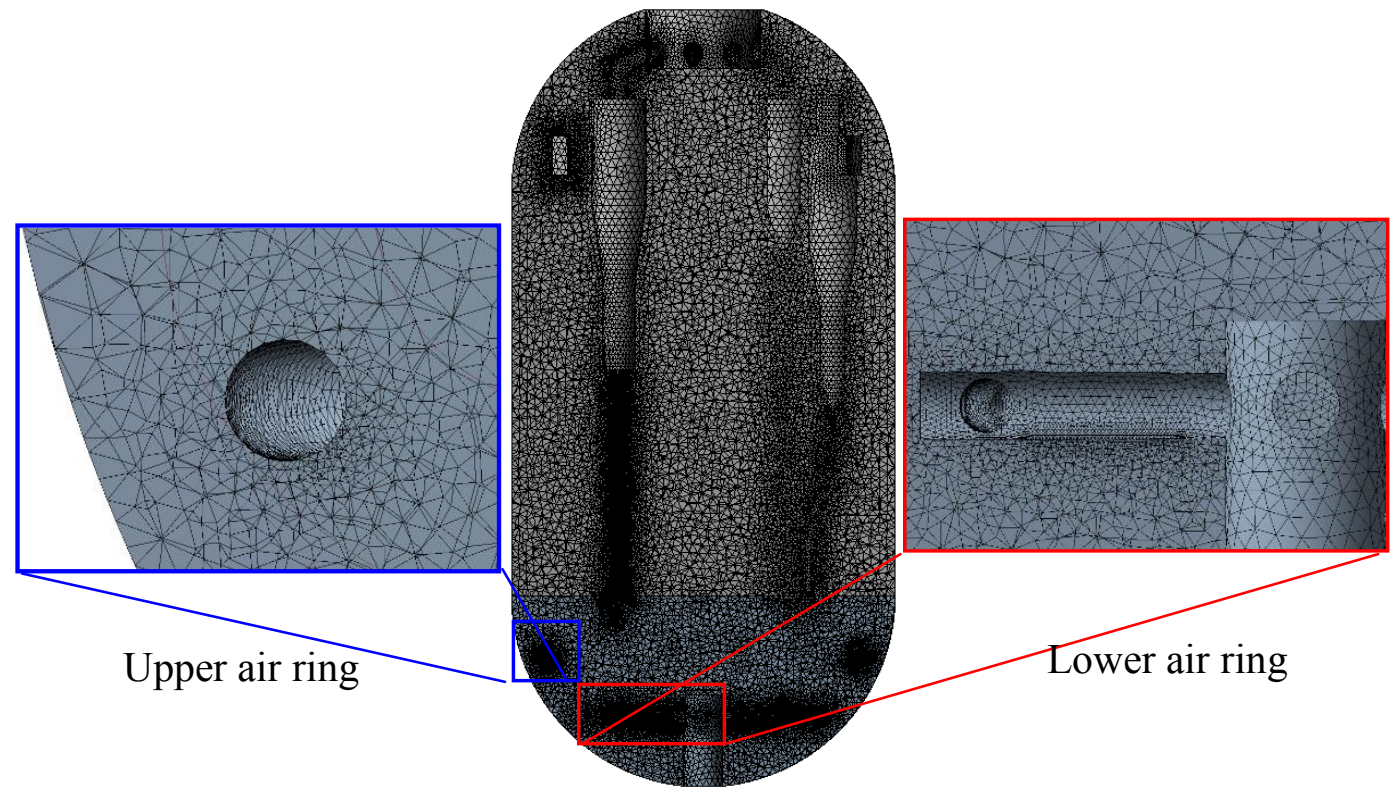

Center cross-section

(b)

Figure 1 (a).Computational domain with boundaries, (b). mesh 
Numerical Simulation and Optimization of an Industrial Fluid Catalytic Cracking Regenerator

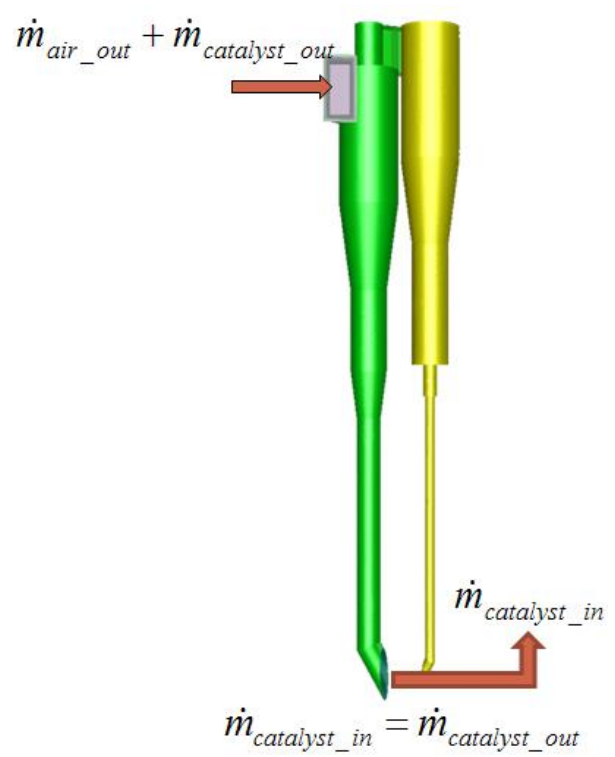

Figure 2 Cyclone boundary conditions 

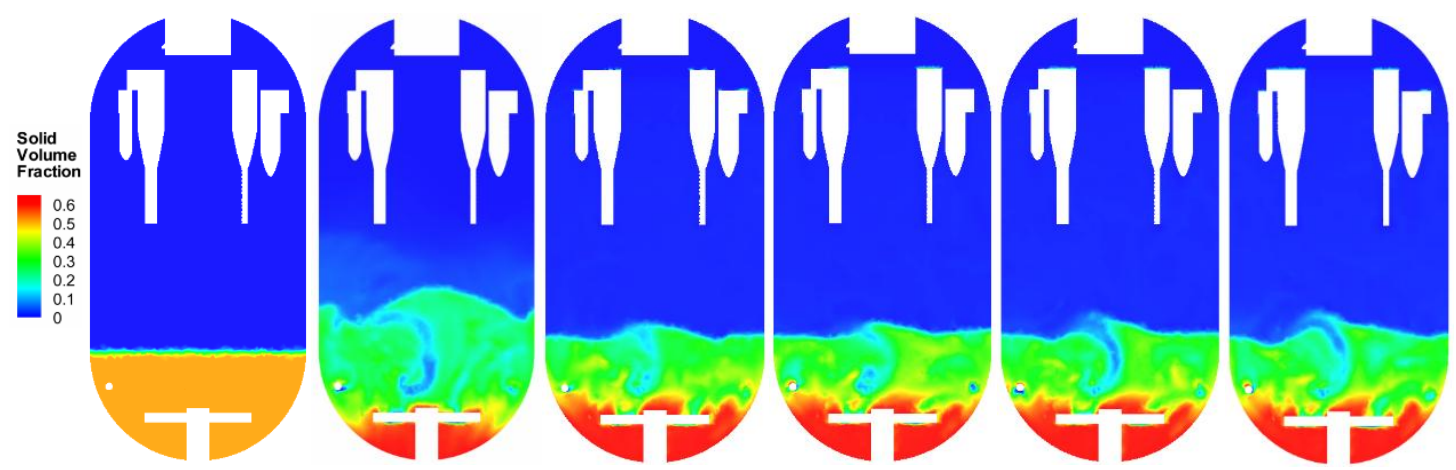

$\mathrm{t}=0 \mathrm{~s}$

$$
\mathrm{t}=10 \mathrm{~s}
$$

$\mathrm{t}=100 \mathrm{~s}$

$\mathrm{t}=300 \mathrm{~s}$

$\mathrm{t}=500 \mathrm{~s}$

$\mathrm{t}=800 \mathrm{~s}$

Figure 3 Solid volume fraction profiles changing with time 
Numerical Simulation and Optimization of an Industrial Fluid Catalytic Cracking Regenerator

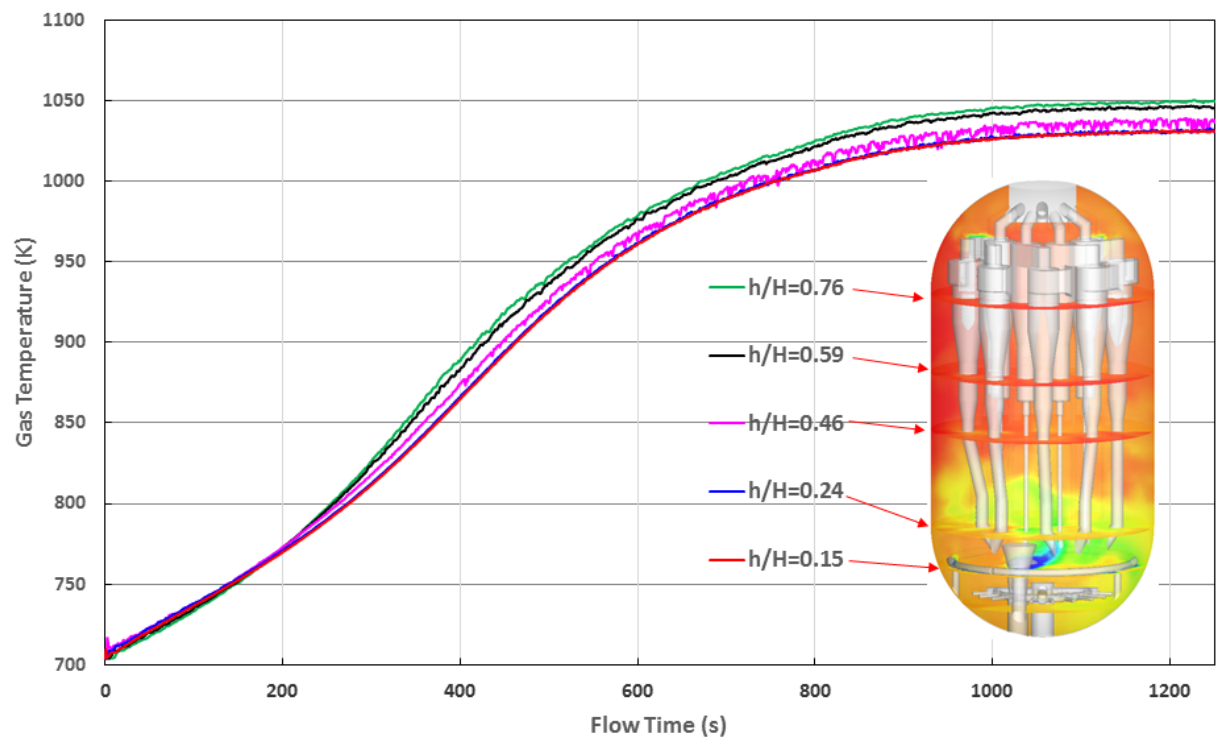

Figure 4 Gas temperature evolution at different levels

along the regenerator height 


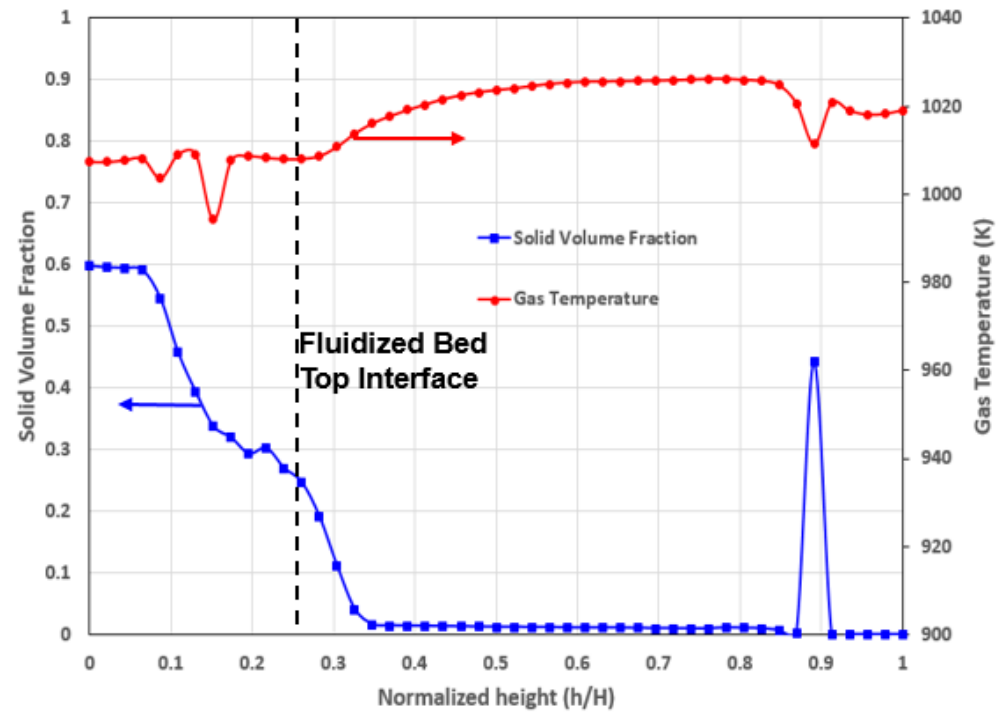

Figure 5 Mass weighted average solid volume fraction and gas temperature along regenerator height 
Numerical Simulation and Optimization of an Industrial Fluid Catalytic Cracking Regenerator

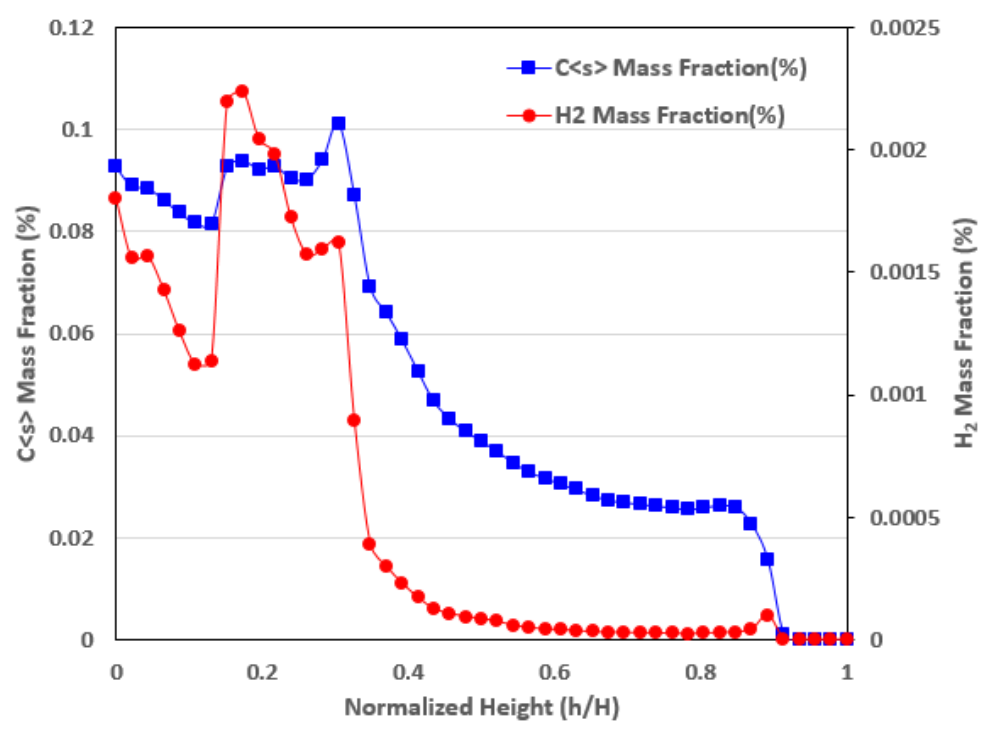

Figure 6 Mass weighted average species mass fraction in solid phase along regenerator height 
Numerical Simulation and Optimization of an Industrial Fluid Catalytic Cracking Regenerator

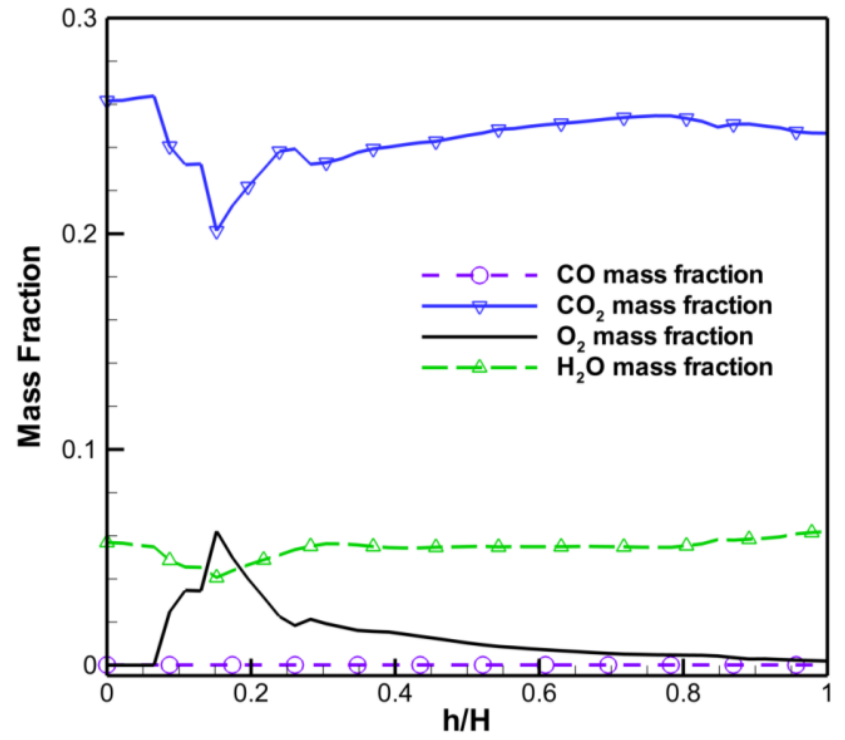

Figure 7 Mass weighted average species mass fractions in gas phase along regenerator height 
Numerical Simulation and Optimization of an Industrial Fluid Catalytic Cracking Regenerator

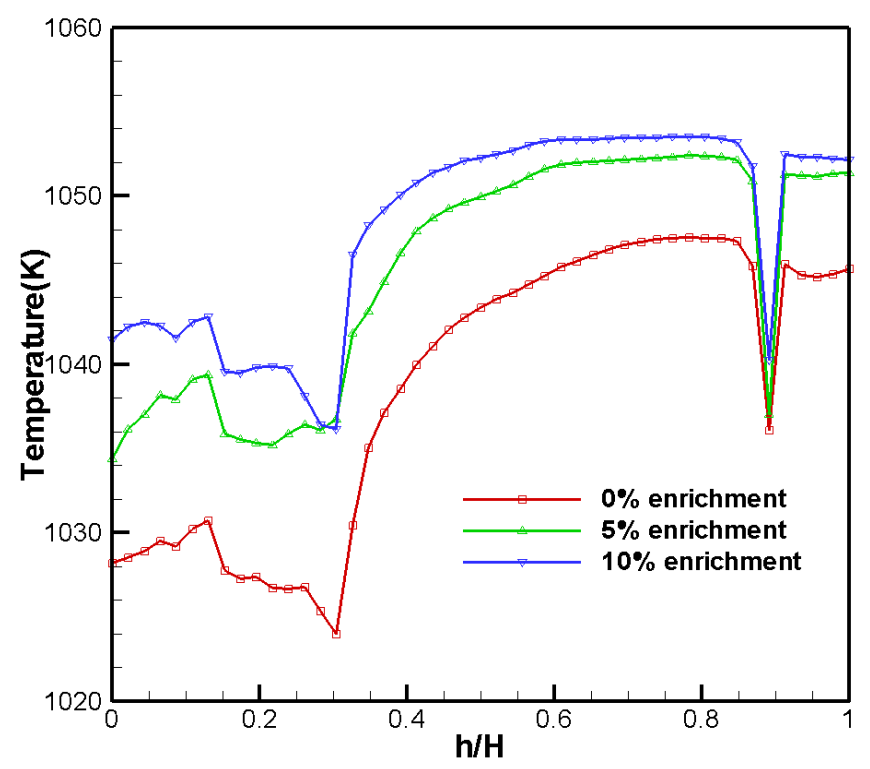

Figure 8 Effect of oxygen enrichments on average gas temperatures along regenerator height 

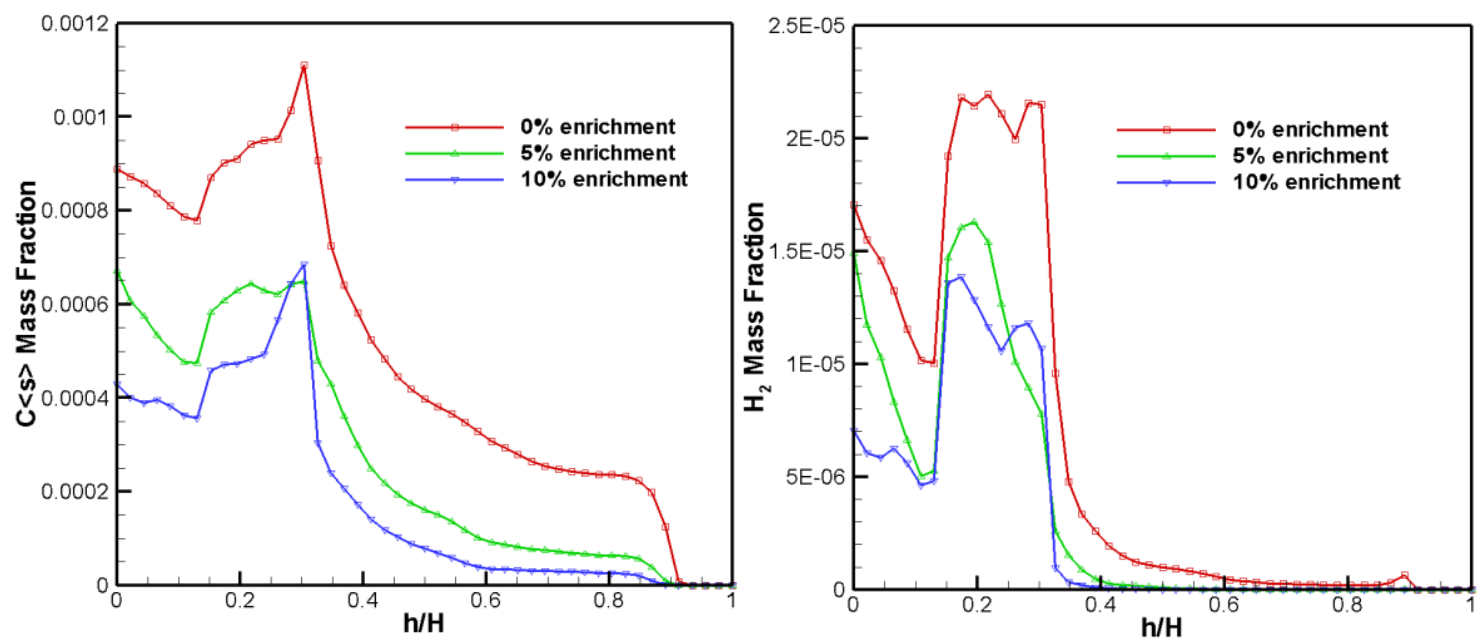

Figure 9 Effect of oxygen enrichments on species $\mathrm{C}<\mathrm{s}>$ and $\mathrm{H}_{2}$ in the solid phase along the regenerator height 
Numerical Simulation and Optimization of an Industrial Fluid Catalytic Cracking Regenerator
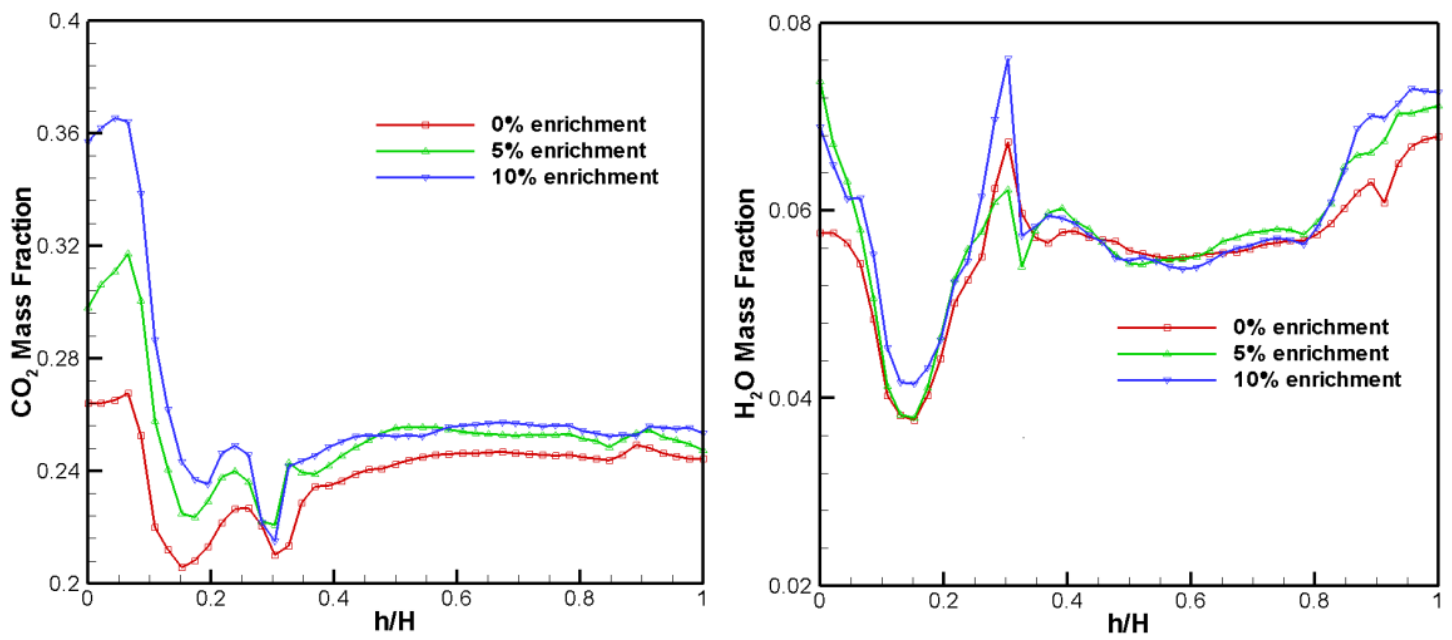

Figure 10 Effect of oxygen enrichments on gas phase species $\mathrm{CO}_{2}$ and $\mathrm{H}_{2} \mathrm{O}$ along the regenerator height 